\title{
A Methodology to Introduce Sustainability into the Final Year Project to Foster Sustainable Engineering Projects
}

\author{
David López, Fermín Sánchez, Eva Vidal, Josep Pegueroles, Marc Alier, Jose Cabré, Jordi Garcia, and Helena García \\ Universitat Politècnica de Catalunya - UPC BarcelonaTech \\ Jordi Girona 1 - 3, 08034 Barcelona \\ david@ ac.upc.edu, fermin@ ac.upc.edu, eva.vidal @ upc.edu, josep.pegueroles@ upc.edu, granludo@ essi.upc.edu, \\ jose.cabre@ upc.edu, jordig@ ac.upc.edu, helena.garcia @ est.fib.upc.edu
}

\begin{abstract}
The introduction of sustainability skills into higher education curricula is a natural effect of the increasing importance of sustainability in our daily lives. Topics like green computing, sustainable design or environmental engineering have become part of the knowledge required by today's engineers. Furthermore, we strongly believe that the introduction of this skill will eventually enable future engineers to develop sustainable products, services and projects. The Final Year Project is the last academic stage facing students and a step towards their future professional engineering projects. As such, it constitutes a rehearsal for their professional future and an ideal opportunity for reflecting on whether their Final Year Project is sustainable or not, and to what extent. It also provides a good tool for reviewing the lessons learned about sustainability during the degree course and for applying them in a holistic and integrated way. In this paper, we present a guide that allows both students and advisors to think carefully about the sustainability of engineering projects, in particular the Final Year Project.
\end{abstract}

Keywords-sustainability; engineering projects; final year project.

\section{INTRODUCTION}

In 2008, the Universitat Politècnica de Catalunya BarcelonaTech took the strategic decision to incorporate sustainability skills into the curricula and to implement them during the process of adaptation to the European Higher Education Area (EHEA) [1]. In 2010, the Barcelona Schools of Informatics and the Telecommunication Engineering SchoolTelecomBCN new degree courses got under way. The main objective was to integrate sustainability into these degree subjects as a natural part of the engineering profession. This work was presented in a communication at a previous FIE Conference [2]. By introducing sustainability concepts in most subjects, students are expected to acquire a holistic and integrated perspective [3].

Nowadays, sustainability skills have already been successfully introduced throughout most of the subjects on the curriculum. However, a new problem has arisen concerning those students who began the degree in 2010 and are now starting the Final Year Project (hereafter FYP). We agree with other authors [4] in the view that the FYP provides the best opportunity for practicing and evaluating professional skills such as sustainability. Indeed, it is essential to work the concept of sustainability throughout different subjects of the curriculum, but the place where a holistic view about sustainability can be obtained is in the FYP, due to the fact that it represents what will be the future main task of the graduates: the engineering projects on which they will work. However, due to constraints such as time frames and expected workloads, students are sometime unable to work on complete projects in their FYP, and focus only on a specific part. Some decisions regarding the sustainability impact of the project may therefore have already been taken by the students' managers or advisors, while students themselves have no say on the issue. Without an appropriate guide, students will only evaluate the sustainability of their work rather than taking into account the sustainability of the whole project and its subsequent impact. The authors of this paper believe that students should ponder projects as a whole and be aware that some decisions may have a deep impact on the environment and society.

We therefore decided to draw up a set of questions to stimulate students to think carefully about the implications of their project. This immediately posed a new problem: how could set of questions be designed so as to help students to mull over the implications of their work? In this paper, we present the methodology we follow for designing and organizing this set of questions. We also present several approaches we have considered that have led us to propose a matrix structure very similar to Felber's Matrix for the Common Good [5]. Our matrix is organized into sustainability values and the project variables affecting these values, with questions designed to encourage reflection and evaluation according to sustainability criteria.

The questions on the final matrix are closely adapted to our own curricula and are therefore difficult to export to other studies. It is for this reason that instead of the final set of questions, we present the organization of the matrix and all the steps in the process that led us to obtain the matrix. However, 
we believe that the main contribution of this paper is the innovative methodology presented herein, which may be adapted to other engineering curricula.

\section{DIFFERENT APPROACHES}

Our proposal is based on a series of questions that invite the engineer to think about the sustainability of the project. One of the main issues is how this set of questions can be organized. In this section we describe the different approaches that arose during our brainstorming sessions, and why they were discarded until we arrived at our solution. The reader should bear in mind that the set of questions must be arranged in such a way that students are prompted to think and to act.

\section{A. Set of procedures/questions}

The most basic approach is a set of questions consisting of a list without any fixed structure that gives engineers complete freedom to provide the answers they deem appropriate.

The advantage of this approach is that it enables a brainstorming process in which all kinds of questions both easy and difficult may be posed. This method can be applied to all types of engineering projects and enables many kinds of fine distinctions to be made. A potential disadvantage is that it may be too general and unstructured, and this lack of order may lead to partial conclusions. Indeed, presented with an openended series of questions, students may very well leave them to the end of the FYP to be answered, thereby leading them to evaluate the sustainability of the project rather than designing a sustainable project themselves, whereas it is our aim that students should consider sustainability carefully throughout the entire project and not just at the end.

\section{B. Questions during a milestone}

In an engineering project, milestones define special moments of the timeline where the project is monitored and evaluated, either internally or by the client. During the milestone, the engineer may pose questions aimed at assessing the project's sustainability, the purpose of which is a review of the completed work and an advance towards the next stage in a sustainable way.

For the particular case of the FYP, we adopt the proposal put forward by Valderrama et al. [6] in which three milestones are set out for the assessment of the FYP: an initial, middle and final milestone. An initial assessment should be carried out after the first few weeks of a project, by which time students have been working on it long enough to have developed a clear approach to the work; they will have analyzed the state-of-the-art of the subject and its viability, as well as established a work plan. A second milestone for monitoring the project in the long term is proposed in the second half of the project, when any dysfunctions in the initial approach can be detected and there is still time to make any necessary corrections. A third and final assessment milestone is then conducted on completion of the work.

Given this three-milestone system, the intuitive implementation of this approach would consist in a set of questions designed to stimulate students to reflect on the sustainability of FYP during each of these milestones.
The problem in this approach arises from the very existence of project milestones. Our milestones are related to the very nature of the academic work rather than to the nature of the engineering project. Limiting the questions to an artificial and reduced milestone system results in an unnatural approach that is far from holistic. It also transforms sustainability analysis into an external obligation rather than a natural response to the challenges of the project.

\section{Questions related to the current project phase}

While we were drawn to the idea of grouping questions into sets to be answered at different points throughout the project, grouping them according the academic needs of the FYP did not seem such a good idea, so we decided to group them according to the phases of an engineering project. The main concept behind this approach is to organize the questions according to the project phases: (i) construction, (ii) use or (iii) dismantling of the project. Thus, the questions may therefore be classified as they evolve from one phase to another over the lifetime of the project. The important difference here is that this approach does not include milestones, and the assessment consists of a continuous process throughout the three phases mentioned above.

The drawback of this approach is that most of the questions will be asked during the construction phase. For example, the sustainable dismantling of the project from an environmental point of view will depend on its correct construction.

\section{Questions arranged according to the three dimensions of sustainability.}

During the process that led us to the previous proposal, we found that we had overlooked the very idea of a sustainable project based on the three pillars of sustainability: environmental, economic and social. Our aim is for our students to consider very carefully the impact of their projects on the environment, on the economy and on society. So the task was to arrange our set of questions according to the three dimensions of sustainability:

- Environmental: the questions could be aimed at drawing a comparison of the ecological footprint before and after the project, at studying the life-cycle of the project, or related to the nine planetary boundaries proposed by the Stockholm Resilience Centre (climate change, ocean acidification, ozone depletion, water use, changes in land use, loss of biodiversity, aerosol loading in the atmosphere, chemical pollution and human interference in the cycle N-Ph) [7],

- Economic: the questions could be aimed at an analysis of the economic viability of the project; its implementation and destruction; whether it can be achieved with fewer resources or less impact, or whether increased costs would be offset by an increase in profits,

- Social: questions could be aimed at studying the social impact on users, workers, beneficiaries and others, or focused on meeting the Millennium Development Goals. 
The strength of this approach resides in that it is a methodology aimed directly at the concept of sustainability. This approach fixes the problem of assigning different questions to the milestones as well as providing the flexibility for a holistic management of the whole project. However, it requires an accurate decision to be made about what point in the design or construction of the project that each of the sustainability dimensions should be considered. Accordingly, we decided to organize the questions within a two-dimensional matrix.

\section{E. Set of questions according to the three dimensions and the current development phase}

This approach is based on the foregoing sections C and D. The main idea is to combine in a matrix the three sustainability dimensions with the phases of a project consisting of planning, development, deployment and evolution, and dismantling, as shown in Table 1.

In the planning column, it is necessary to consider the initial

\begin{tabular}{|l|l|l|l|l|}
\hline & Planning & Development & $\begin{array}{l}\text { Deployment } \\
\text { and } \\
\text { evolution }\end{array}$ & Dismantling \\
\hline Economics & & & & \\
\hline Social & & & & \\
\hline Enviromental & & & & \\
\hline
\end{tabular}

Table 1: Matrix with the sustainability dimensions and project phases.

situation in each of the economics, social and environmental dimensions before acting. The development column will include commissioning costs and associated transients. The deployment and evolution column will include the questions regarding the use and status of the project in the three dimensions, once the product is installed. Finally, the destruction column considers what happens when the project ends.

While this approach is more comprehensive than the previous proposals, it suffers from the same weakness as those presented previously. Indeed, while preparing the project we are planning its development, and consequently most of the questions will be in the planning column. Moreover, the likelihood of the project being one of sustainable engineering depends largely on how the planning phase is conducted. We believe that arranging the questions on a timeline excludes a holistic view of the project, and this complete view is something that we consider necessary for a sustainable project. It was at this point that we realized that we needed a fresh point of view, so we studied the literature outside the field of engineering with the aim of finding other approaches to the evaluation of sustainability.

\section{F. The common good economy}

Our final approach is based on the economy for the common good matrix developed by Christian Felber [5]. The economy for the common good is an open economic project in which companies are encouraged to use an alternative methodology in order to achieve a sustainable economy. This project is aimed at both the market and planned economies. While this is not a paper about economics, in what follows we describe the main ideas of Felber's work. We use the proposed methodology to build our own matrix, but do not discuss the principles of the common good economy.

The purpose of the economy for the common good is to resolve the contradiction between the social values sought by society as a whole (honesty, appreciation, trust, responsibility, solidarity, sharing, etc) and the values that sometimes drive the economy (selfishness, greed, envy, irresponsibility, distrust, etc.)

The measure of economic success at the macroeconomic level uses the calculation of Gross Domestic Product (GDP), but GDP does tells us nothing about whether the wealth distribution among citizens is fair; whether confidence or fear spread throughout society; whether ecosystems are overexploited; whether the situation is one of peace or war, or whether we live in a democracy or a dictatorship, and so on.

At the business level, success is measured by net worth, but this parameter tells us nothing about whether jobs are being created or destroyed, whether the company produces organic products or weapons, or whether the company damages the environment, etc.

Felber suggests that we measure the success of companies in terms of their contribution to the common good and cooperation, and they are rewarded according to their contribution. For example, national or local governments may give priority by means of a public tender to companies that contribute most to the common good.

To measure the contribution of business to the common good, Felber proposes a matrix in which the columns contain the most common values found in the constitutions of countries (dignity, solidarity, environmental sustainability, social justice, democratic participation and transparency) and the rows include all those groups associated with companies (suppliers, financiers, employees, owners, customers, products, etc). Table 2 shows a simplified version of the matrix; the complete version can be found at http://www.gemeinwohl-oekonomie.org/en/content/creatingcommon-good-balance-sheet). By using this matrix, Felber analyzes a number of criteria such as wage differences between men and women; the quality of the jobs; participation in politics; environmental impact and so on. It is interesting to note that some criteria provide positive scores, while others yield negative scores. Thus, companies are unable to obtain a good score by focusing only on a few criteria, but should try to consider them all. The overall assessment of these values would allow consumers to make fully informed choices of companies and their products.

The most interesting feature of the Felber matrix is that it is composed of several dimensions, and questions can be arranged according to these dimensions.

\section{OUR PROPOSAL}

Our proposal combines the different points of view discussed in the preceding sections. Inspired by Felber's ideas, a matrix containing a list of indicators has been developed. Table 3 shows the basic scheme of the proposed matrix. Each cell in the matrix is an indicator, which in turn gives rise to a set of questions related with the idea behind the indicator. 
Here the Socratic Method is followed, in the sense that the process is based on asking and answering questions to stimulate critical thinking and to illuminate ideas. The answers will guide the sustainability report of the project, which should be written as a separate chapter in the report of the final project.

Arranging the stages of the project into matrix rows has been discarded because, as already stated, most decisions must be taken at the very beginning of the project, and thus the only stage that is considered in a row is planning. Furthermore, an analysis of the results and the existing risks is performed, and these two factors constitute the two remaining rows.
The columns correspond to the sustainability dimensions (environmental, economic and social), since this model is the one with which students are most familiar and therefore the easiest for them to follow. It will be easier for the students to work with the three dimensions separately, but they should be treated holistically when the student becomes an engineer.

In line with Felber's model for the common good matrix, all the cells of our matrix are weighted. Unlike Felber's matrix, however, some of the cells of our matrix may contain both positive and negative values. In our proposal, students must evaluate the sustainability of their FYP from the indicators contained in Table 3, through the particular set of

\begin{tabular}{|c|c|c|c|c|c|}
\hline & \multicolumn{5}{|c|}{ Common values in most Constitutions } \\
\hline $\begin{array}{l}\text { CONTACT } \\
\text { GROUP }\end{array}$ & $\begin{array}{l}\text { Human } \\
\text { dignity }\end{array}$ & Solidarity & $\begin{array}{l}\text { Ecologic } \\
\text { sustainability }\end{array}$ & Social justice & $\begin{array}{l}\text { Participation in } \\
\text { politics }\end{array}$ \\
\hline Providers & \multicolumn{5}{|c|}{ Ethical management of supply and demand $(90)$} \\
\hline Funders & & & & \multicolumn{2}{|c|}{$\begin{array}{l}\text { Ethical management of the } \\
\text { funding }(30)\end{array}$} \\
\hline $\begin{array}{l}\text { Employers / } \\
\text { Owners }\end{array}$ & $\begin{array}{l}\text { Quality of jobs } \\
\text { and equality } \\
\text { (90) }\end{array}$ & $\begin{array}{l}\text { Fair } \\
\text { distribution of } \\
\text { the work load } \\
(50)\end{array}$ & $\begin{array}{l}\text { Promotion of } \\
\text { ecological } \\
\text { behavior (30) }\end{array}$ & $\begin{array}{l}\text { Fair } \\
\text { distribution of } \\
\text { wealth }(60)\end{array}$ & $\begin{array}{l}\text { Internal } \\
\text { democracy, } \\
\text { transparency } \\
(90)\end{array}$ \\
\hline $\begin{array}{l}\text { Clients / } \\
\text { Products / } \\
\text { Services }\end{array}$ & $\begin{array}{l}\text { Ethical selling } \\
(50)\end{array}$ & Solidarity (70) & $\begin{array}{l}\text { Ecological } \\
\text { products and } \\
\text { services (90) }\end{array}$ & $\begin{array}{l}\text { Social aspects } \\
\text { of the products } \\
\text { (30) }\end{array}$ & $\begin{array}{l}\text { Enhancement of } \\
\text { social and } \\
\text { ecological } \\
\text { values }(30)\end{array}$ \\
\hline $\begin{array}{l}\text { Social } \\
\text { context }\end{array}$ & $\begin{array}{l}\text { Social effect } \\
\text { of services and } \\
\text { products }(90)\end{array}$ & $\begin{array}{l}\text { Contribution } \\
\text { to the common } \\
\text { good }(40)\end{array}$ & $\begin{array}{l}\text { Reduction of } \\
\text { ecological } \\
\text { footprint }(70)\end{array}$ & $\begin{array}{l}\text { Minimization } \\
\text { of the earning } \\
\text { distribution } \\
(60)\end{array}$ & $\begin{array}{l}\text { Participation on } \\
\text { decision } \\
\text { making } \\
\text { processes }(30)\end{array}$ \\
\hline $\begin{array}{l}\text { Negative } \\
\text { criteria }\end{array}$ & $\begin{array}{l}\text { Breaking work } \\
\text { rules }(-200)\end{array}$ & $\begin{array}{l}\text { Hostile } \\
\text { takeover } \\
(-200)\end{array}$ & $\begin{array}{l}\text { Big ecological } \\
\text { footprint } \\
(-200)\end{array}$ & $\begin{array}{l}\text { Difference in } \\
\text { salaries }(-200)\end{array}$ & $\begin{array}{l}\text { Non-disclosure } \\
\text { of payments } \\
\text { to lobbyists } \\
(-200)\end{array}$ \\
\hline
\end{tabular}

Table 2: Simplified balanced sheet of the common good economics.

\begin{tabular}{|c|c|c|c|}
\hline Sustainable? & Economic & Social & Environmental \\
\hline Planning & Economic viability & Improves quality of life & Resource analysis \\
\hline Score & $0: 10$ & $0: 10$ & $0: 10$ \\
\hline Results & $\begin{array}{c}\text { Final cost vs } \\
\text { prevision }\end{array}$ & $\begin{array}{c}\text { Social environment } \\
\text { impact }\end{array}$ & $\begin{array}{c}\text { Resource } \\
\text { consumption }\end{array}$ \\
\hline Score & $-10: 10$ & $-10: 10$ & $-10: 10$ \\
\hline Risks & $\begin{array}{c}\text { Adaptation to } \\
\text { changing scenario }\end{array}$ & $\begin{array}{c}\text { Social damage } \\
\text { damage }\end{array}$ & $\begin{array}{c}\text { Environmental } \\
\end{array}$ \\
\hline Score & $-20: 0$ & & $-20: 0$ \\
\hline Total score & $-90: 60$ & & $-20: 0$ \\
\hline
\end{tabular}

Table 3: Proposed questions to assess sustainability in an FYP or an engineering project. 
questions in every indicator. Each project would therefore have an associated value (either positive or negative) related to its level of sustainability. It is necessary to emphasize that the aim of the proposal is not to evaluate the sustainability of the FYP, nor to achieve a perfectly sustainable FYP. The aim is to make students aware of the sustainability and to realize that decisions made in the absence of information or knowledge may have a negative impact on the final project sustainability.

Each indicator should be evaluated (and justified) as follows:

- Planning indicators: evaluation from 0 to 10

- Results indicators: evaluation from -10 to 10

- Risks indicators: evaluation from -20 to 0

Notice that the absolute value of the negative evaluation of the risks indicators doubles the positive evaluation of the planning indicators. This is because score in any of these indicators will inevitably have a very negative effect on the final score, so they cannot be ignored. Lack of symmetry yields a minimum -90 score, while the maximum score may reach 60 points.

The final questions should not be raised at a specific point in the project, such as a milestone, but should remain active in the mind of the designer or engineer throughout the life-cycle of the project, from the collection of requirements and the definition of the problem to its final dismantling. In this sense, we apply these engineering principles from the "cradle" of a project to the "cradle" of whatever comes next, as proposed by McDonough et al. [8] (Cradle to Cradle approach) .

\section{DISCUSSION}

\section{A. On the validity of our model}

To the best of our knowledge, this is the first time a systematic set of questions addressing the sustainability of the FYP has been proposed. Thus, we cannot compare our proposal with other existing works or demonstrate the benefits of the proposed methodology. Furthermore, in this paper we just present the developed framework to design this set of questions. We have just finished the first version of the questions, and the first results will be available in February 2015. In the near future, after acquiring practical experience from several developed FYPs, we expect to present an accurate quantitative and qualitative analysis of the results. However, the final results will depend on the suitability of the questions, and the set of questions depends strongly on idiosyncrasies of the curricula. Here, we must confine ourselves to describing a methodology that can be adapted to other engineering curricula.

\section{B. Questions for achieving a holistic view}

From the beginning, we have sought a holistic view of sustainability that avoids an artificial approach, but rather a natural and global integration of sustainability in a global project. We have also tried to cover the entire scope of the project, since engineers should not just be workers but aware of and responsible for everything surrounding their projects.
Furthermore, we believe that the use of questions is pedagogical and useful in academic environments, since it directly stimulates undergrad designers to think and reflect.

In our table, we propose some indicators that must give rise to a set of questions, the nature of which depends on the particular type of degree we wish to evaluate or the kind of project we are dealing with. It is not necessary to formulate the questions in detail, and neither do they require an accurate answer; rather they should be simplified to facilitate the adaptation of the table to any type of project.

Some examples of questions are as follows: What is the origin of the primary resources used in the project? Is the new process more efficient than the process it replaces? Does the new process reduce the level of pollution of the industrial activity? Is the product designed for an easy and cheap recycling process? Does it imply changes in the behavior of end users? As stated above, the nature of the questions depends on the very nature of the project.

The way in which these questions are formulated is not designed to elicit intelligent or informed answers, or answers based on actual data or projections based on plausible information. Rather the questions are aimed at arousing the consciousness of current and future engineers as well as raising awareness of the issues that each question addresses. They are even suitable for a project in which freedom of decision regarding the development and control over the expected results is as limited as that found in some FYP or research projects.

The questions are not aimed at eliciting simple "right" or "wrong" answers, but are designed to stimulate "awareness". We are aware that the responses to these questions may often be of the type: "The question does not apply to the project context", or "I do not have enough data, criteria or skills to answer." However, awareness of one's own ignorance may well sow the seed of new research projects that lead to greater knowledge and awareness of the issue.

Finally, we wish to address what some authors refer to as the fourth dimension of sustainability: the institutional dimension. We consider this to be a transverse dimension, without which the other three dimensions cannot be successfully addressed. Clearly, if the laws of a country or a community do not regulate all the bounds and parameters regarding the sustainability of engineering projects, we are unable to ensure that such projects will be consistent with sustainability. Rules and regulations are needed for governing sustainability requirements for engineering projects, and at present such regulations are virtually non-existent in all countries.

\section{FYP and engineering projects}

Although the work presented in this paper is focused on FYP, the ideas discussed herein can also be used in general engineering projects. In order to include sustainability in the FYP, we believe that an approach based on questions for students to consider is more appropriate than the design of a standard template for assessing the sustainability of the project once it is completed. Our ultimate goal is for students and future engineers to perceive sustainability as an inherent part 
of every project, and to learn how to apply this idea in their professional careers.

Students should be encouraged to think about the project in depth. Specifically, they should analyze the context of the project and the effects of its implementation. By using this information, students should ask themselves a series of questions to be considered during the design and implementation of the FYP. Our list of questions is merely the beginning: students should be regarded not as technicians in charge of a specific task, but as future engineers with the capacity to develop a global view of the problems to solve.

Furthermore, it is essential to differentiate the concept of FYP as an academic assignment from the actual implementation and deployment of the final outcome of the FYP. In other words, the FYP covers all work carried out by the student during the execution of the project: the project proposal; the study of the state-of-the-art; the design, implementation, evaluation and drafting of the report, among other tasks, and concluding when the project is presented and defended. Alternatively, we define PPP (Project Put into Production) as the set of tasks and resources during the project life-cycle materialized in an actual implementation, which includes commissioning, use during its lifetime and of course the final dismantling.

Since a sustainability analysis conducted exclusively on the FYP would provide only incomplete information, estimating the effects of including sustainability in a project and the cost of producing the FYP should be assessed separately from the costs and sustainable benefits of a PPP. Both effects are mutually independent, and identifying them separately is crucial for the success of the project. Note that there might be cases of FYP with a surprising level of sustainability that have a completely unsustainable PPP implementation. Conversely, an FYP may show no sustainable criteria, while the PPP may be completely sustainable. Perhaps a somewhat hyperbolic example may be used to illustrate our point: on November 14, 2012, a petition originating on the White House website "we the people" proposed the construction of a "Death Star" space station similar to that depicted in the Star Wars movies. Nearly 35,000 signatures were received in support in just a few weeks, but fortunately the idea was rejected. This provides a good example for us: a space station similar to the "Death Star" is clearly a good project from the strictly engineering point of view; every phase of the project could be conducted in a sustainable way. However, the final use of the completed project raises serious questions about its sustainability, especially since its purpose is the destruction of planets.

No doubt projects exist where discussions about sustainability make little sense at a first glance. It is nonetheless true, however, that basic aspects of sustainability must be always considered, while other aspects may be optional depending on the type of project. In any case, the fact that a project is sustainable or not should constitute no impediment for its development as an academic work. It is important to point out that the FYP is an academic event, and in this sense it is useful for assessing the level of knowledge of a student, even in those cases in which the proposed work is not sustainable. Moreover, the degree of sustainability referred to in a project may vary depending on the time at which its sustainability was assessed.

Finally, a further key point to evaluate is the importance accorded to sustainability in the overall FYP. While we may assume that a student has tackled the project with rigor and professionalism, and hence with the application of sustainable criteria, it may be a good idea to try to quantify the number of hours that should be devoted to analysing the sustainability of the project. As an example, in our school the FYP carries 15 ECTS. The European Credit Transfer and Accumulation System (ECTS) is a standard for comparing the study attainment and performance of students of higher education across the European Union and other collaborating European countries. In Spain, one ECTS corresponds to 25 hours of study, so an FYP of 15 ECTS should be equivalent to 450 hours. Professional skills such as communication and sustainability carry a weight of $40 \%$ of the FYP final grade, and since seven skills must all be evaluated with the same weight, one may conclude that approximately 25 hours should be devoted to each skill. Obviously, this figure is a simplification, but it nevertheless provides a good approximation of the minimum amount of time that should be devoted to studying project sustainability in our school, especially in view of the fact that sustainability must be considered holistically in the FYP. There is therefore little doubt that devoting sufficient time to sustainability assessment is justified.

\section{CONCLUSIONS}

The need to take sustainability into account when planning an engineering project arises naturally if we wish to be congruent with both our environment and ourselves, but at present there are virtually no mechanisms for defining and evaluating the sustainability of an engineering project.

Starting from a general point of view, and without losing sight of the original objective (guiding students and engineers towards the introduction of sustainability into their projects), we conducted a study that led us to a simple and comprehensive outcome.

On this basis, we analyzed different approaches aimed at producing a series of questions using different criteria finally employing the economy for the common good criteria proposed by Felber. Instead of dealing separately with project dimensions, we believe that sustainability must be considered holistically in engineering projects. The matrix of "The economics for the common good" provided us with the key to a holistic approach, and the two dimensions of this matrix constitute the final building block for our proposal.

The combination of an approach based on questions, the three dimensions of sustainability and Felber's matrix form the basis of our proposal for defining and assessing sustainability criteria in an engineering project, and in particular an FYP.

In the specific case of FYP, we believe that it is vital to distinguish the concept of FYP as an academic assignment, leading to an end product as a result of the eventual implementation and use of the product created. The FYP 
covers all work done by the student during the course of the academic project, and the project includes the entire set of tasks and resources used during the project life-cycle in an eventual implementation.

The final results of this work are aimed at raising the awareness of undergraduate students and engineers by means of a simple and direct approach, ranging from the definition of requirements phase of the project to its completion, thereby ensuring an a priori consideration of sustainability that may influence the development of the project.

\section{ACKNOWLEDGMENT}

This work has been carried out with the support of Institute of Educational Sciences (ICE) of the UPC- BarcelonaTECH through the RIMA-VISCA group; the CCD (Centre de Cooperació pel Desenvolupament) and the MiPLE project and the Ministry of Science and Innovation Spanish, under the project coded TIN2010 - 21695 -C02- 02.8.

\section{REFERENCES}

[1] The Official Bologna Process website, http://www.ond.vlaanderen.be/hogeronderwijs/bologna. Last visited april 2014.
[2] D. López, F. Sánchez, J. Garcia, M. Alier, J. Piguillem, and M. Velasco. "Introducing Sustainability and Social Commitment Skills in an Engineering Degree". 41st Frontiers in Education Conference. Rapid City, SD, USA, October 12-15, 2011. Pp. S2C1-6.

[3] M.K. Watson, R. Lozano, C. Noyes, and M. Rodgers. "Assessing curricula contribution to sustainability more holistically: Experiences from the integration of curricula assessment and students' perceptions at the Georgia Institute of Technology." Journal of Cleaner Production, Vol. 61 pages 106-116. December 2013.

[4] J.L. Sánchez, C. S. González, and S. Alayon. "Evaluation of transversal competences in the final year project in engineering." Proceedings of the 22nd EAEEIE Annual Conference (EAEEIE), June, 2011.

[5] C. Felber. Die Gemeinwohl-Ökonomie - Das Wirtschaftsmodell der Zukunft, ISBN 978-3-552-06137-8 2010.

[6] E. Valderrama, M. Rullán, F. Sánchez, J. Pons, C. Mans, F. Giné, L. Jiménez, and E. Peix. "Guidelines for the final year project assessment in engineering". 39th ASEE/IEEE Frontiers in Education Conference. San Antonio, TX. October 2009.

[7] Johan Rockstom et al. "A safe operating space for humanity". Nature. Vol. 461, 24 September 2009.

[8] William McDonough, Michael Braungart, Paul T. Anastas, and Julie B. Zimmerman. "Peer reviewed: Applying the principles of green engineering to cradle-to-cradle design". Environmental Science and Technology 37(23): 434-441. 2003.

[9] Robert G. McLaughlan. "Instructional Strategies to Educate for Sustainability in Technology Assessments". Int'l Journal of Engineering Education 23(2):201-208, 2007. 